\title{
Refusal of planning consent for the Docking Shoal offshore wind farm: stakeholder perspectives and lessons learned.
}

\author{
BROADBENT, I.D. and NIXON, C.L.B.
}




\title{
Blinded manuscript
}

\section{Refusal of planning consent for the Docking Shoal offshore wind farm: stakeholder perspectives and lessons learned.}

\begin{abstract}
The Docking Shoal project was developed by Centrica as part of The Crown Estate's Round 2 of UK offshore wind licensing. After 8 years of development, the project was ultimately refused planning consent by the Secretary of State for Energy and Climate Change. The current study seeks to explore the factors behind this decision, as well as its impact and legacy for the offshore wind industry from the perspectives of key stakeholders including the project developer, a statutory consultee, and the regulatory body. Key findings are aligned along themes of the consenting process, environmental impacts, views and reactions to the decision, and lessons learned. The study concludes that the Docking Shoal decision centred on issues of impacts upon seabird populations of the Docking Shoal project itself, as well as the potential cumulative impacts of neighbouring offshore wind project developments. The study also reveals that the Docking Shoal project marked a shift in approach by the regulator towards a more holistic and strategic assessment of cumulative impacts, taking into account the combined effects of all foreseeable neighbouring projects in the pipeline. Finally, the paper discusses some of the key issues highlighted by the Docking Shoal project that have continued to impact upon the development and deployment of offshore wind projects.
\end{abstract}

\section{Keywords}

Offshore wind, consenting, environmental impact assessment, cumulative impacts

\section{Introduction}

Since the installation of the UK's first offshore wind turbine at Blyth in 2001, the UK offshore wind industry has experienced significant growth. Indeed, the industry can no longer be described as "fledgling", with 7.9 GW of installed capacity and more than 1900 turbines currently operational in UK waters as of February 2019 [1].

In the UK, The Crown Estate manages the seabed and coastal assets out to 12 nautical miles, and also owns the rights to generate electricity from offshore renewables on the UK continental shelf $[2,3]$. The Crown Estate grants exclusivity rights and Agreements for Lease (AfL's) to project developers, and has administered a series of development rounds for offshore wind in UK waters, resulting in the 
current UK offshore wind portfolio of $35.2 \mathrm{GW}$ either in operation or at various stages of development [4].

Round 1 projects were designed to provide investor confidence in offshore wind technology, whilst minimising the cost of financial support schemes to Government; consequently Round 1 projects were limited to a maximum of 30 turbines each, and were typically between 70 and $100 \mathrm{MW}$ in project capacity, as turbine capacity at the time was limited to 2-3 MW [5]. As of 2018, 13 Round 1 projects had been developed, totalling 1.2 GW in capacity [6].

In contrast, Round 2 projects announced in 2003 were larger in ambition (up to $900 \mathrm{MW}$ capacity per project, totalling 7.2 GW), and were accompanied by increases in turbine capacity [5]. Additionally, offshore wind projects were supported by the introduction in 2002 of a new financial incentive scheme, the Renewables Obligation and the Renewables Obligation (Scotland), known as the "RO", which gave greater confidence in the industry to investors and project developers. The Docking Shoal project which is the subject of this paper was a Round 2 project, and was awarded an AfL capacity of $540 \mathrm{MW}$ in 2004 [7].

Subsequently, in 2008, nine additional zones were identified for lease in Round 3 involving even larger development areas and potential capacity (up to $33 \mathrm{GW}$ in total), and a further development round was held in Scottish territorial waters (STW) in 2011 [5,8].

As the development rounds have proceeded, project sites have tended to be further from shore and larger in area, with everincreasing turbine sizes and rotor diameters [4]. These projects have presented greater challenges for project developers and regulators in terms of technical complexity and the assessment of potential environmental impacts, both in isolation and in combination with nearby projects at various stages of development.

A number of projects have failed to proceed and have been cancelled or abandoned prior to submission of a consent application, due to technical, environmental and/or commercial reasons. However, despite these challenges, 14 out of the original 17 Round 2 sites proceeded to commissioned projects, with only one, Docking Shoal, being refused planning consent [6].

Indeed, Docking Shoal was the first offshore wind farm project in the UK to be refused planning consent by the Secretary of State after a determination had been sought $[9]^{1}$. There has only been one subsequent case where planning consent has been refused by the Secretary of State, for the Round 3 Navitus Bay project in 2015 [10].

${ }^{1}$ Determination in this context means the rendering (by the Secretary of State) of a final decision on whether consent for the offshore wind project is granted or not. 
In addition to having the best wind resources and the largest offshore wind portfolio in Europe, the UK is also home to large breeding populations of seabirds that are protected under the EU Habitats and Birds Directives $[11,12]$. The potential impacts on protected populations or sites from any proposed offshore wind farm development must be assessed and considered; it is also necessary (under the EU Habitats and Birds Directives) to consider the potential negative impacts of the combination of multiple projects in addition to assessing the impacts of individual projects in isolation.

It is therefore unsurprising that the potential impacts of offshore wind projects upon seabird populations have been at the centre of controversy in the UK [13], and impacts upon one particular species of seabird, the Sandwich Tern, were central to the Docking Shoal decision [9].

This study seeks to investigate the key obstacles that led to the decision to refuse planning consent for the Docking Shoal offshore wind farm, by exploring stakeholder perspectives from individuals familiar with the project at the time, and also by examining the decision letter that outlined the Secretary of State's reasoning for refusing consent. The paper also discusses the legacy of the Docking Shoal decision, identifying any lessons that could be learned from the failed project that might be relevant to current and future offshore wind projects.

\section{Consenting of offshore wind and context for the Docking Shoal project: literature review}

The construction of offshore wind projects requires appropriate consent from the governing authorities responsible for the areas potentially impacted by the projects. Government policy and legislation acknowledges the need to protect the marine environment and acknowledge stakeholder issues, whilst at the same time enabling the development of offshore renewable technologies and meeting national renewable energy objectives [14, 15]. Additionally, as the growth in offshore renewable development continues apace, the cumulative impacts of multiple marine projects provides an increasing source of uncertainty, delay and project risk [16, 17, 18].

As a result of these pressures, the consenting process can be lengthy and costly [19-24]. Prior to the project developers being in a position to apply for a consent determination, there may be several years of requested activities including scoping, site characterisation, environmental data collection and stakeholder consultation. However, the data and studies required to support Environmental Impact Assessments (EIAs) vary considerably both within and across EU Member States, limiting the ability to address this issue on a European scale [14, 25]. 
The risks of developing projects in unsuitable areas can be partly mitigated by the processes of marine spatial planning and by carrying out Strategic Environmental Assessments (SEA) of areas that are thought to be broadly suitable for development. The SEA process in the UK is underpinned in EU law by the European Directive $2001 / 42 / E C$ 'on the assessment of the effects of certain plans and programmes on the environment' $[26,27]$. This allows stakeholders and the wider public an opportunity to review and comment on the development areas.

In the UK, SEAs have preceded competitive tender processes before leases are awarded to developers and detailed EIA programmes are commissioned as part of specific project developments. In 2002, acknowledging that the greater scale of Round 2 projects required a more strategic approach than in Round 1, the Department of Trade and Industry identified areas for potential development [28], including the Thames Estuary, Liverpool Bay and the Greater Wash (in which the Docking Shoal project was situated). A SEA was undertaken for each area ahead of The Crown Estate's Round 2 offshore leasing process [29]. A subsequent UK Offshore Energy Strategic Environment Assessment (OESEA) was published in 2009 to underpin the Round 3 process [30].

The UK consenting process has enabled the development of multiple projects and the largest operational offshore wind capacity in the world as of the end of 2017 [31]. On occasion, however, unforeseen issues identified during data gathering and analysis become insurmountable and projects such as the Atlantic Array, Argyll Array and Shell Flats have failed or been abandoned prior to submission of a consent application [ 6 32].

In the case of London Array Phase II, consent for the Round 2370 MW Phase II project was dependent upon a Grampian Condition [3335], which required the developer to demonstrate that the additional turbines did not impact upon the population of Red-throated Divers Gavia stellata and the area's status as a Special Protected Area². This would have required an additional three years' worth of data collection, and in the light of this and other technical constraints the developers decided to withdraw from Phase II [35].

Such withdrawals and project abandonments are perhaps to be expected if EI A and consultation processes are carried out effectively. Detailed site-specific studies might reveal hitherto unforeseen issues in zones that were initially thought at the SEA stage to be suitable for development; these might include unfavourable seabed conditions or geological issues, or high concentrations of seabirds, marine mammals or other marine wildlife [6 32, 35].

2 A Grampian Condition prohibits development authorised by the planning permission until a specified action has been taken. 
Once project developers have gathered and analysed environmental data, and engaged with the relevant stakeholders, a consent application is submitted to the relevant governing authorities who will then consider the evidence and make a decision as to whether or not the project should receive consent to proceed. In England and Wales, the legislative landscape has changed considerably since the turn of the century. At the time of the Docking Shoal project, offshore wind farms were subject to Section 36 (s36) of the Electricity Act 1989, and the final decision on a s36 consent determination lay with the Secretary of State for Energy and Climate Change [36]. Subsequently, this process has been replaced by the Planning Act, 2008 [37].

Detailed ElA studies and stakeholder engagement during the planning process can lead to proposed project envelopes being altered to mitigate environmental impacts (e.g. altered numbers, layout or siting of turbines, modified cable routes or onshore works); these mitigation steps are normally sufficient to allow the modified projects to progress towards a consent determination being sought. Therefore, by the time that a consent application has been submitted and a determination sought from the consenting authority, it is expected that the developer has identified and addressed the majority of the issues that have emerged during the process.

Nevertheless, as a consequence of the aforementioned SEA, EIA and consultation processes, it is extremely rare for an offshore wind project to be refused consent once a determination has been sought, and indeed our review of the literature has identified that there have only been two such cases in the UK $[9,10]$, relating to the Docking Shoal and Navitus Bay projects.

Docking Shoal was originally proposed as a $540 \mathrm{MW}$ capacity project comprising up to 108 turbines during the Round 2 offshore licencing process. An agreement for lease from The Crown Estate was secured by the project developer (Centrica) in 2004, with a planning consent application submitted in 2008. The application for consent for the Docking Shoal wind farm was dealt with under s36 of the Electricity Act 1989. Consent was ultimately refused by the Secretary of State for Energy and Climate Change in 2012 [9].

\section{Methodology}

\subsection{Research design and structure}

This study has used qualitative data to discuss and draw conclusions on the consequences of a refusal of planning consent for an offshore wind farm. The methodology adopted follows the approach taken by Leete et al. [21], who researched the attitudes of investors to wave and tidal technologies, and Wright (2016) [15] who studied industry perspectives on the Scottish marine governance framework for ocean energy. Although both of these studies were focusing on wave and 
tidal technologies, the methodology can equally well be applied to offshore wind.

The research will be exploratory in nature as the researchers aim to discover new knowledge and insights about the impacts of a refused planning consent on a cross-section of stakeholders in the offshore wind industry. An inductive approach will be followed as this can enable research to draw conclusions and develop meanings and theoretical ideas from a rich and varied dataset $[38,39]$.

The research for this paper consisted of one phase of initial exploration of the literature and a separate phase of in-depth interviews with stakeholders familiar with the Docking Shoal project.

Phase 1: A review of the literature relating to the consenting of offshore wind in the UK context was carried out. This included a detailed review of the official decision letter of the planning refusal for Docking Shoal. Following this review (presented in Section 2 of this paper), main themes emerged that were translated into questions to guide the semi-structured interviews in Phase 2.

Phase 2: A series of three in-depth, semi-structured interviews was conducted during a five month period in 2016.

\subsection{Participants}

The participants that were invited to take part in this study had all been closely involved in the proposed Docking Shoal project.

Participants were invited to take part by way of a short email explaining the nature and context of the proposed study as well as the purpose of the research. Some participants requested sight of the general interview questions in advance of the interview.

A cross-section of stakeholders were interviewed as can be seen from Table 1. The authors acknowledge that the number of interview participants in this study is small, partly because by the time of the research many professionals who had been involved in the Docking Shoal project had moved on to new roles. The authors also invited others to participate from relevant organisations; three of whom declined to be interviewed for the project. Despite the small number of participants, their own specific experience and intimate knowledge of the Docking Shoal project and the depth of interviews conducted, provided the basis for sound analysis.

It should be noted that the views expressed by participants reflect personal views of the experiences during the Docking Shoal project and do not necessarily reflect the views of the organisations with which participants were formerly affiliated or employed. 
Table 1

Nature of participants interviewed in this study.

Docking Shoal

Participant type

Number

Project developer team

1

Regulator

1

Statutory Nature Conservation Body (SNCB)

1

\subsection{Interview structure}

Due to the geographical location of interviewees, all interviews were carried out by telephone, and were all approximately one hour in length.

Each interview was started with an explanation of the context and overall aim of the research. The researchers clarified that interviews would be focusing on the interview themes shown in Table 2 below. 
Table 2

Interview Themes for Docking Shoal

Theme

Guiding questions / topics

Consenting Process

1. Experience of application process

2. Request to put application into abeyance

3. Length of time to reach a decision

4. Financial and reputational cost

Environmental Impacts

1. Strategic Environmental

Assessment (SEA)

2. European Sites

3. DECC Appropriate

Assessment

4. Population Viability

Analysis / Maximum Mortality

Threshold

The DECC Decision

1. Views/reaction to the reasoning in the Decision

Lessons Learned

1. Factors which could have produced a different outcome

In order that data obtained from the interviews would have sufficient consistency to enable analysis, participants were asked a pattern of general questions under each of the interview themes. However, care was taken to use open questions and avoid closed or narrow questions so as not to introduce researcher bias [39]. Overall, a flexible approach to interviewing was maintained, so that as much information as possible was obtained from participants.

\subsection{Data analysis}

With the participants' permission, audio files of the interviews were recorded. Interview audio files were transcribed. Each interview transcript was checked by the authors and then sent to participants in order that they could ensure that the transcript represented a true account of their interview.

The transcripts were then coded into themes using QSR International's NVivo 11 qualitative data analysis software [40] by 
one author. The coded transcripts were checked for validity by the other author.

\section{Results}

\subsection{Consenting Process}

\subsubsection{Experience of application process}

Participants explained that there were actually three applications for s36 consent being considered concurrently by DECC in the Greater Wash area. Centrica applied in December 2008 for consent to build Docking Shoal $14 \mathrm{~km}$ from the North Norfolk coast, and followed this in January 2009 with an application for consent to build Race Bank $27 \mathrm{~km}$ from the same coast. The third application being considered was made by Warwick Energy in April 2009 to construct an offshore wind farm, Dudgeon, $32 \mathrm{~km}$ from the North Norfolk coast. The respective locations of these projects are shown below in Figure 1 alongside other offshore wind projects in the Greater Wash area.

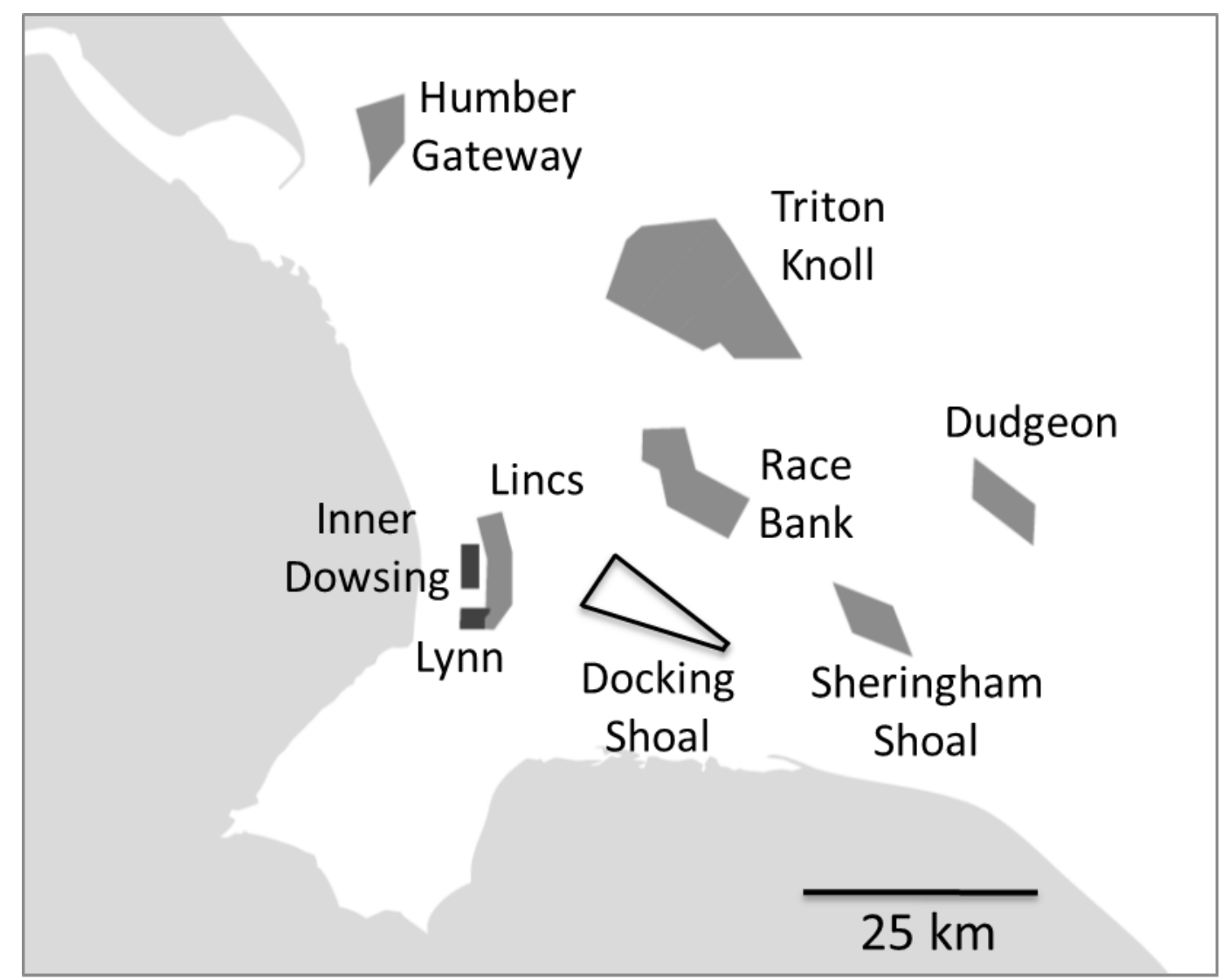

Figure 1: Offshore wind project locations in the Greater Wash area. Round 1 projects: Lynn and Inner Dowsing. Round 2 projects: Docking Shoal, Sheringham Shoal, Dudgeon, Race Bank, Triton Knoll, Humber Gatew ay (Adapted from [5]) 
The Lynn and Inner Dowsing projects had been commissioned and operational since 2009, whilst the Sheringham Shoal project was granted consent in November 2008 and was operational by 2012. Similarly the Lincs project was granted consent in October 2008 and was fully commissioned in 2013. Triton Knoll would not receive consent until 2013, and began construction in 2018 [ 6.

Participants highlighted that DECC indicated initially that they would be using the "building block" approach to consenting Docking Shoal. This means that the impacts of Docking Shoal were to be considered along with all other projects already consented or in accordance with those projects which were ahead of Docking Shoal in the relevant consenting processes. Using the "building block" approach, the application for the first project would be acceptable in terms of impacts, the second project added cumulative impacts to the first project, and so on until a tipping point was reached where the impacts of projects are unacceptable, and further projects cannot be consented.

One participant elaborated on the "building block" approach, "If you are at the back of the queue you're less likely to get consent. The problem with that approach is that the one at the back of the queue might be overall a better environmental project than the one at the front of the queue. So by consenting the one at the front of the queue, you have actually stopped all of the other projects from happening".

Another interviewee commented that given the application of the "building block" approach, there was "there was a real rush, particularly on Centrica's part, to get projects in". In light of this, it was felt by this participant that not enough consideration was given to problems relating to the Docking Shoal project or to some of the issues that could have been resolved at an early stage.

However, post-submission of the planning application for Docking Shoal, and following advice from the statutory nature protection bodies, participants highlighted that DECC changed from a "building block" to a more holistic and strategic, cumulative approach to consenting. Under the strategic cumulative approach, the impact of Docking Shoal would be considered along with all other projects, including those reasonably foreseeable but yet to be submitted for consent and those which were behind Docking Shoal in the consenting process. It is clear from Sections 5 and 6 of the decision letter [9] that the Docking Shoal decision was evidently influenced by the potential impacts of neighbouring project proposals, primarily Race Bank and Dudgeon but also Sheringham Shoal and Triton Knoll that were all considered as part of the Appropriate Assessment [41] (Sections 4.2 and 4.3 below). 


\subsubsection{Request to put application into abeyance}

In 2011 Centrica requested that the Secretary of State place their application for consent in abeyance until such time as further environmental information relating to bird impacts could be provided by them. The interviews revealed that a large body of data - two to three years' worth - had been collected in advance of the application for consent on the usage of the Docking Shoal location. However, two participants raised the fact that there was a lack of data relating to the impacts of built wind farms on Sandwich Terns to support the modelling in terms of avoidance rate and actual impacts. In terms of actual impacts, one participant commented that there was a "data void". Despite this, an interviewee on the project development team was confident that if Centrica's application was put into abeyance, within a couple of years they could gather data on bird avoidance behaviour.

However, the request to place the application in abeyance was refused by the Secretary of State [9]. The regulator explained that "placing an application in abeyance does not remove it from the planning system", and that the Secretary of State is required "in accordance with the Habitats Regulations to take the Amended Application into account when assessing the in combination effect to all the applications for s36 consent which are in the planning system" [para 5.8, reference 8]. Given that the Secretary of State did "not consider that it would be appropriate to leave the Docking Shoal application in abeyance" [ para 6.4, reference 9] the only other option for the developer would be to withdraw the application and resubmit at a later stage.

\subsubsection{Length of time to reach a decision}

It took DECC three years and seven months (from 9 December 2008 to 6 July 2012) to issue their decision on the Docking Shoal application for planning consent under s36 of the Electricity Act 1989.

One participant commented that the time taken for the decision to be made was "far too long". Another participant explained that straightforward applications would normally take around two years to process, but that thornier applications, such as Docking Shoal, would take somewhere between two to five years to process. Using this general guide, it was considered that the decision-making period on Docking Shoal followed fairly typical timeframes for s36 applications.

Interestingly, the regulator participant did not consider that having more staff resources at DECC at the time would have helped to reduce the decision-making period, stating "it's easier in some respects when a complex issue all sits with one person's head. Rather than several heads all with competing information". 


\subsubsection{Financial and reputational cost}

It is self-evident that developers will have made a substantial financial commitment to a project by the time that they submit their application for planning consent. In addition to the financial loss, the refusal to grant consent has a reputational impact to the developer.

A participant on the project development team estimated that Centrica incurred costs in the region of $f 10 \mathrm{~m}$ for the work done prior to and in conjunction with submitting the s36 application for Docking Shoal. This is in line with previous estimates of offshore wind project development and consenting costs; Accenture (2012) [20] suggested that development and consenting costs could be responsible for 5$10 \%$ of the CAPEX costs of an offshore wind farm. RenewableUK (2014) [24] found that whilst early Round 1 projects typically spent $£ 1 \mathrm{~m}-\mathrm{f} 2 \mathrm{~m}$ on development, some of the subsequent Round 3 projects had accrued $£ 20 \mathrm{~m}-£ 30 \mathrm{~m}$ in development costs.

The same participant noted that whilst $f 10 \mathrm{~m}$ is fairly significant, they are dwarfed by the total costs of an offshore wind project, citing the example of Race Bank which was a $£ 2$ bn project.

Concern about costs and strain on resources was not only a worry for the developer. A participant for a SNCB commented that "everyone is very mindful of what happened .... with Docking Shoal and they don't want to end up there, especially when you're spending millions and millions of pounds. We equally don't want to put in loads of resources to something that is potentially not going to go forwards".

\subsection{Environmental I mpacts}

\subsubsection{Strategic Environmental Assessment (SEA)}

As part of the Offshore Wind Farm Development: SEA (R2 Wind) [29, 30], a risk based analysis was carried out to highlight the main concerns for offshore wind farm development in the strategic areas.

One research participant acknowledged that the Round 2 SEA had pointed out the difficulties which would be posed by Sandwich Tern to the possible wind farm developments in the Greater Wash. The SEA highlighted the risk of collision mortality from the turbines with Sandwich Tern in the Greater Wash unless more information is known about avoidance rates and avoidance behaviour. The participant felt that the SEA's concern about Sandwich Tern was "almost ignored ... in a race for the line to get projects in for submission so the first projects would be fine and consented" under the "building block approach".

Another participant was critical of the SEA (R2 Wind) process saying that it had not been sufficiently robust when identifying the environmental impacts. The participant went as far to say that the 
SEA (R2 Wind) was "fundamentally flawed", pointing out that it had not even considered the cabling issues which would be encountered in the Greater Wash.

A further interesting point raised by the participant from an SNCB was that by the time that consent decisions were being made on Docking Shoal, Race Bank and Dudgeon, there had not been enough time to learn any lessons from Round 1 of offshore wind farm leasing. This suggests that there needs to be a sufficient period of time between conclusions of one round and the start of the next leasing round for reflection and improvement. Indeed by the time Round 3 had been announced in J une 2008, only five Round 2 wind farms had gained consent, and none had begun construction [6].

Even after an area has been formally identified via SEA as suitable, the decision as to where to site a project within the area is vitally important.

One interviewee emphasised choosing appropriate locations for development and mentioned two key issues in relation to this. Firstly, developers would be wise to find cabling routes to take the electricity onshore that are outside designated sites. Secondly, developers should avoid putting projects in areas where significant bird populations are foraging. Whilst acknowledging the benefits of renewable energy, this participant stressed that it must be in the right locations: "We shouldn't be pushing forwards at all cost because it's green energy".

\subsubsection{European Sites [as defined by the Conservation of Habitats and Species Regulations (2010) as amended]}

The Conservation of Habitats and Species Regulations 2010 required the Secretary of State to consider whether the proposed Docking Shoal wind farm would be likely to have a significant effect on a European Site, either alone or in combination with other projects. Three European Sites were identified as being potentially impacted by the Docking Shoal project [9]:

- North Norfolk Coast Special Protection Area (SPA);

- The Wash and North Norfolk Coast Special Area of Conservation (SAC); and

- Inner Dowsing, Race Bank and North Ridge candidate SAC.

By law, the Secretary of State should only grant the s36 consent if it could be shown that the projects would not adversely impact the integrity of these three European Sites unless it is demonstrated that there are no alternatives, there are imperative reasons of overriding public interest and compensatory measures are in place.

Interviewees highlighted the critical importance of the North Norfolk Coast SPA in the considerations of the Docking Shoal project. The North Norfolk Coast SPA encompasses much of the northern coastline 
of Norfolk in eastern England [42]. It is a low-lying barrier coast that extends for $40 \mathrm{~km}$ from Holme to Weybourne and includes a great variety of coastal habitats. The great diversity of high-quality freshwater, intertidal and marine habitats results in very large numbers of waterbirds occurring throughout the year. For over 35 years, there has been a large population of Sandwich Terns (Sterna sandvicensis) on the North Norfolk coast. It is made up of two colonies: one based at Scolt Head (managed by Natural England) and the other based at Blakeney (managed by the National Trust).

Sandwich Terns from these colonies regularly feed outside the SPA in adjacent coastal waters up to 60 kilometres off the North Norfolk coast. This includes the locations of all three offshore wind farm projects, Docking Shoal, Race Bank, and Dudgeon that were considered in the 2012 decision [9]. Unusually, there was considerable data available about this tern colony as stated by an interview participant from a SNCB: "we have quite a lot of information about...the natural variations of that population, for the last 30 years".

\subsubsection{DECC Appropriate Assessment}

The Secretary of State for DECC carried out an Appropriate Assessment (AA) of the proposed Docking Shoal development in combination with the offshore wind farm s36 applications at Race Bank and Dudgeon, together with the offshore wind farm being constructed at Sheringham Shoal (which had received consent in November 2008) and the application for a development at Triton Knoll [41] ${ }^{3}$.

The AA looked at effects of Docking Shoal, Race Bank and Dudgeon on the three European Sites listed in Section 4.2.2. Interviewee participants focused mainly on the effects of Docking Shoal and neighbouring wind farms on Sandwich Terns from the North Norfolk Special Protection Area as this was the paramount obstacle (although clearly not the only environmental impact) hindering consent being granted. Other impacts of the wind farm mentioned in the Appropriate Assessment and Decision letter were on harbour seals, on Annex I habitats such as Sabellaria reef, salt marsh, intertidal mudflats and sand banks and cockle beds from the cabling [41, 9]. I mpact on seascape was mentioned by an interviewee from a SNCB as being a concern in combination with the consented Sheringham Shoal project "both during the day but especially at night time in terms of lighting and the change of the seascape character under construction of Sheringham Shoal".

3 "Appropriate Assessment" as required by Regulation 48 of the Habitats Regulations 1994 implementing Article 6(3) of the Habitats Directive (92/43/EEC) [reference 11]. 
DECC's AA identified that the key likely significant effects of the Docking Shoal, Race Bank and Dudgeon wind farms on the Sandwich Tern were collision mortality, disturbance and displacement of birds from feeding areas during construction as well as disturbance and reduction in prey availability during construction [41].

The AA reasoned that a maximum mortality threshold of 94 Sandwich Terns from the North Norfolk Coast SPA per annum was an appropriate threshold when assessing the potential for an adverse effect on wind farm development in the Greater Wash. The DECC decision letter stated that "there will be no adverse impact on the integrity of the North Norfolk Coast SPA, either alone or in combination with other plans or projects, with regard to the effect on the Sandwich Tern population on the basis of the above conclusions so long as the annual mortality threshold of 94 breeding Sandwich Terns across all the Greater Wash wind farms considered in the Appropriate Assessment is not exceeded" [para 5.11, reference 9].

The AA concluded that there were two ways in which it would be possible to limit the annual mortality of breeding Sandwich Terns to 94 birds. One option would be to refuse consent for the Docking Shoal and grant consent for Race Bank and Dudgeon. The second option would be to limit the initial stage of Docking Shoal alongside the s36 applications for Race Bank and Dudgeon by consent conditions; in other words, to restrict the capacity of all three projects. The decision letter issued by the Secretary of State states that "either option would be acceptable" [para 5.12, reference 9].

\subsubsection{Population Viability Analysis and Maximum Mortality Threshold}

Given that over thirty years of data were available, JNCC and Natural England were able to request that Centrica commission a Population Viability Analysis to inform the AA [41]. Its purpose was to model the Sandwich Tern population of the North Norfolk Coast SPA ascertaining what additional impacts the population could withstand. All of the participants were keen to discuss the PVA and Maximum Mortality Threshold, reflecting the controversy which had surrounded these analyses during the consenting process.

The decision letter states that PVA authors suggest a loss after 25 years (i.e. operation of wind farms) of $5 \%$ to $10 \%$ of the reference Sandwich Tern population size might be regarded as offering a reasonable chance of retaining population and site integrity. This equates to an annual harvesting level of 98 to 157 birds [para 5.10, reference 9].

A participant from the then regulator talked about the painstaking work which had gone into the PVA, the consultations which had taken place on it, and finally how DECC had settled on the threshold of 94 birds in its AA. The participant said that the decision, "may well have 
been made partly on science and partly on a hunch. That's the thing with these decisions, the science isn't perfect".

However, interviewees stated that JNCC and Natural England disagreed, arguing that the maximum mortality threshold should be lower, at 75 birds per annum. J NCC and Natural England refuted the conclusion of the AA that there would be no adverse effect on the Sandwich Tern population using an annual mortality threshold of 94. They lacked confidence in the justification of DECC's choice of collision risk modelling (CRM) methodology in the $A A$ and also believed that there was inherent uncertainty about the avoidance rate used [para 5.9, reference 9]. An interviewee for a SNCB acknowledged that J NCC and Natural England had faced criticisms of being overly precautionary, but countered that for them, this threshold was a risk-based approach: "we worked very hard over a couple of years to work with the developers and their consultants to come up with a risk-based approach which was the 75 birds, as far as we were concerned. That was a risk-based approach for us".

An interviewee in the project development team criticised the fact that the DECC AA provided a fixed number (94) as being the maximum mortality threshold. The interviewee elaborated that the PVA was undertaken to provide a range, not a fixed number, especially given that it had been studying an open biological system. This creates difficulties in discriminating the effects of offshore wind farms from other concerns. "The North Norfolk population of Sandwich Tern isn't a static population. So Sandwich Terns don't always return to their natal environment to breed....terns which are born in North Norfolk, for instance, will then go off to Scandinavia and vice-versa. So it's an open system. The PVA only modelled a closed system, so modelled a very small population of the European massive population."

Given that the PVA concluded that annual harvesting of 98 to 157 birds would lead to a loss of 5 to $10 \%$ of the reference population size after 25 years, an interviewee from the project development team thought that the threshold figure should have been much higher than DECC's adopted 94, and that DECC was being overly precautionary. Although the interviewee felt that the PVA was probably the best way of looking at the impact on the tern population, it was considered that all the parties became "far too focused on the numbers and missed the point of what was happening". This resonates with a comment from another participant who said that in essence "it was a numbers game". Despite these criticisms of PVA and weaknesses in its subsequent interpretation, none of the participants during the interviews proffered a more suitable alternative technique. 


\subsection{The DECC Decision and reasoning}

\subsubsection{Views on the reasoning given in the DECC Decision}

In DECC's decision letter [9], the Secretary of State picks up on the conclusions from the Appropriate Assessment. The heart of DECC's reasoning is found at paragraphs 6.2 and 6.3. Paragraph 6.2 reads, "it is the Secretary of State's view that refusal of consent for Docking Shoal (and consenting Race Bank and Dudgeon to their full capacities) would be more efficient overall in terms of implementing UK renewable energy generation policies in a way that is consistent with the environmental protection obligations imposed on the Secretary of State by the Habitats Regulations, than granting consent to the proposed Development with restrictions on first phase build (and with similar restrictions for Race Bank and Dudgeon)."

In paragraph 6.3 of the Decision letter, DECC expanded that since Docking Shoal's location was "closest to the North Norfolk Coast SPA and the foraging areas used by Sandwich Terns, it was predicted to kill on average significantly more breeding Sandwich terns from the North Norfolk Coast SPA per turbine (0.84) than the other two sites ( 0.45 for Race Bank and 0.31 for Dudgeon) and that more generation capacity is likely to be delivered by two schemes (up to $1136 \mathrm{MW}$ ) than the initial phase of three constrained schemes (up to 1080MW)." The authors were interested to find out how DECC's decision was received.

A participant for the then regulatory body expressed the view that by cutting the "worst offender", DECC had let the other two projects survive. DECC had also been extremely aware that the decision it reached had to be one that would provide investor confidence. A participant in the project development team said that there was a "bittersweet" sentiment at Centrica regarding the decision, as "if you look at the press statements from the day obviously Centrica is pleased to note that Race Bank is consented". This participant expressed the view that refusing Docking Shoal and consenting the other two wind farms to full capacity was cleaner for DECC, surmising that much more work would have been involved for DECC had they decided to consent all three projects but under phases. The participant also alluded to the fact that these were the last projects to be consented under s36 of the Electricity Act 1989 in England before the transition to the Planning Act 2008, and suggested that DECC was keen to get these applications completed. One interviewee expressed a personal opinion that the decision to refuse Docking Shoal was positive as "it was recognised that the first project wasn't necessarily the best project", and that the projects with lower impact were taken forward. The same interviewee was pleased that the Secretary of State did not opt for consenting all three projects under a phased approach because it was felt that it can be very difficult to obtain the necessary data to enable the subsequent phases of such projects to go ahead. 


\subsection{Lessons Learned}

\subsubsection{Assessment of cumulative impacts}

A recurrent theme of the interviews were the drawbacks of regulators applying a "building block" approach to consenting offshore wind farm projects. First, the "building block" approach puts too much pressure on developers to get applications in fast without giving appropriate consideration of difficulties relating to their project. It encourages "a race for the line", and may not allow for sufficient time to perform the robust scientific assessments to support consent. Also, under this approach, respondents highlighted that it is possible to end up with the worst environmental outcome rather that the best. The Docking Shoal case demonstrated a move away from the "building block" approach, with the application of a more strategic view of the in-combination cumulative effects of the neighbouring projects. This is discussed further in Section 5.1.

\subsubsection{Data and environmental impact assessment}

Interviewees highlighted that a more significant and credible evidence base is urgently needed on the impacts of different bird species around built offshore wind farms. Only when this exists will it be possible to issue more informed consents. One research participant was adamant that "good science is required to produce good consenting decisions."

Two research participants agreed that, at the time of the decision on Docking Shoal, there was a distinct lack of completed studies on collision risk, avoidance rates and, more generally, about how birds interact around wind turbines. The third research participant did not speak in such detail on this point, but also noted that "the science isn't perfect. You are trying to predict how many birds will collide with the turbine blades. The science has improved somewhat [since the Docking Shoal decision] but it's still not perfect".

\subsubsection{Stakeholder engagement}

RenewableUK [23] highlighted the need for open, early and frank dialogue, and this is further emphasised in the guidance and advice given by Natural England for developments of NSIP projects [43]. The participants in the current study agreed that genuine developer engagement with stakeholders from project inception to submission of the consent application is vital.

The participant from an SNCB emphasised that for them a lesson learned from Docking Shoal was the need to be very clear and upfront about what is and is not acceptable from their perspective of an SNCB. It was considered that there is nothing to be gained from looking into something that they definitely know will be unacceptable. 
Since the Docking Shoal decision, the legislative framework has changed, and NSIPs including offshore wind projects over $100 \mathrm{MW}$ are subject to the Planning Act 2008. A participant from an SNCB acknowledged the strengths of the Planning Act 2008 evidence plan process in helping to address issues earlier on in the pre-application stage of a Development Consent Order (DCO) application. This participant advocated early input into the NSIP process, even if it is to say that a project is not a good idea for various reasons.

\section{Discussion}

\subsection{Shift in regulatory approach to cumulative impact assessment}

As described in Section 4.4.1, participants highlighted that the Docking Shoal decision signalled a shift in the approach taken by the regulator in its consideration of in-combination cumulative impacts from multiple neighbouring projects. The difference in approach is illustrated in Figure 2, where four hypothetical projects are shown under consideration over an unspecified period of time. In the "Building Block" example (Figure 2a), projects are considered in sequential fashion, depending on the order in which the original consent applications were submitted. In the example shown in Figure $2 a$, the fourth project to be submitted is ultimately refused consent, as it adds to the in-combination cumulative impact of the three previously consented projects beyond levels acceptable to the regulator. However, the third project, which is the greatest single contributor to the environmental impact, is granted consent.

In the "Strategic Cumulative" example (Figure 2b), all foreseeable projects are assessed by the regulator at the same time, irrespective of the timing or order of the original applications. This allows an overall assessment of in-combination cumulative environmental impacts to be made together with other factors, including individual project capacity, economics and risk. In the "Strategic Cumulative" case, the third project to be submitted is refused consent whilst the three less harmful projects are allowed to proceed. 


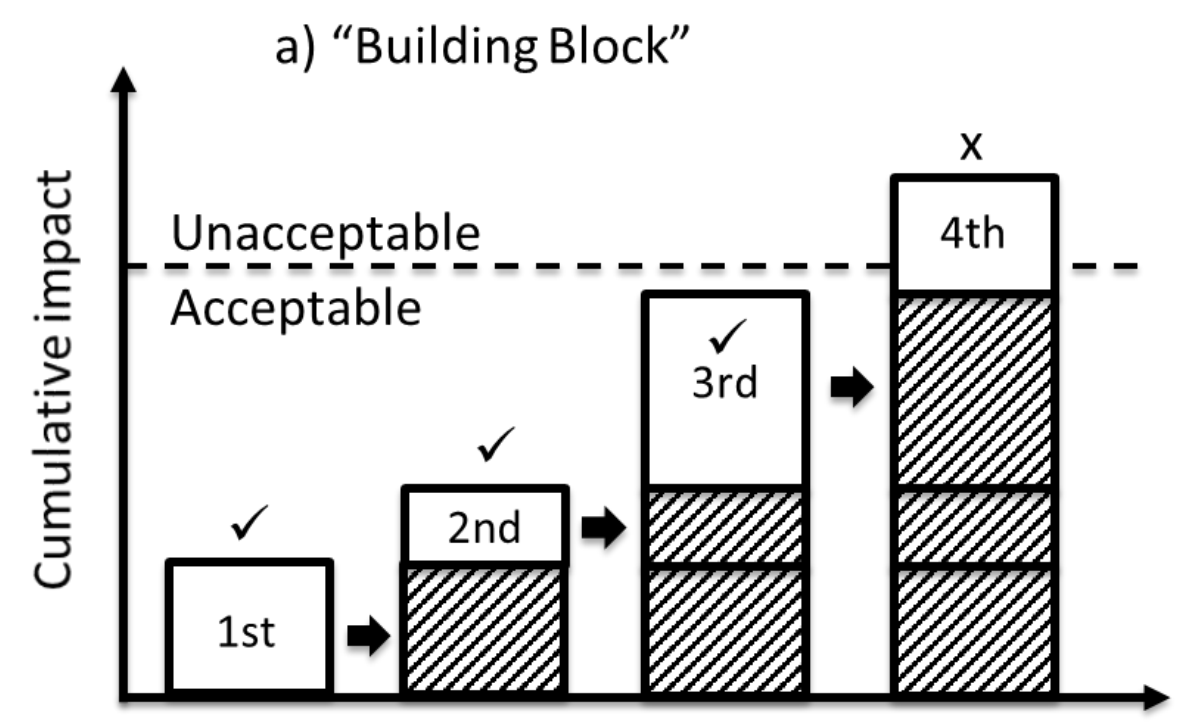

Timing of Consent Determination

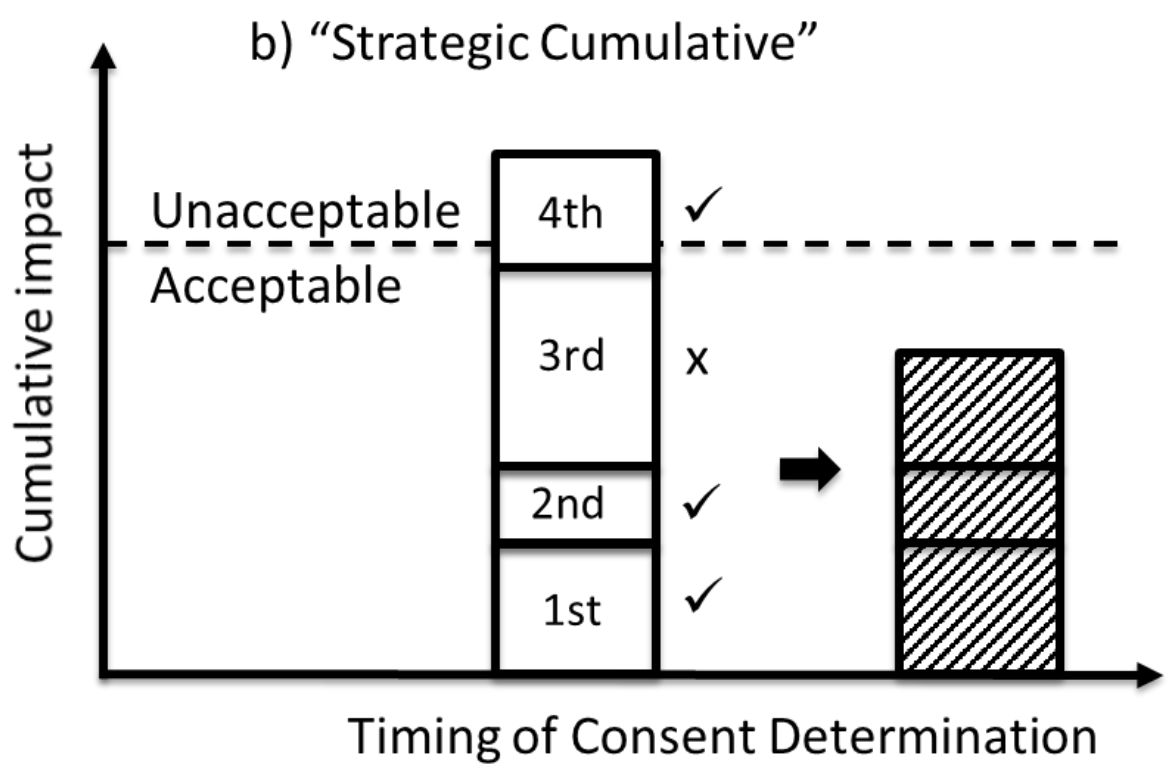

Figure 2: "Building Block" vs "Strategic Cumulative" approaches to project consenting. Shaded boxes and ticks indicate projects approved. $X$ denotes project refused consent. Dotted line indicates hypothetical acceptable limit of in-combination cumulative environmental impact. 


\subsection{Difficulties with cumulative approaches to offshore wind impact assessment.}

Despite the move away from the "building block" approach described above, the assessment of cumulative impacts is still fraught with difficulty and uncertainty. Green et al. (2016) discuss these issues [13], bemoaning the "lack of sound science" in assessing the environmental impacts of offshore wind farms, particularly in relation to seabirds. They highlighted flaws and deficiencies in collision risk models, evaluating population-level impacts, and acceptability thresholds. Cook and co-workers [44] also highlight the sensitivity of collision risk models to a number of assumptions, as well as the lack of understanding around seasonal and spatial impacts on avoidance behaviour.

A recent manifestation of these issues occurred during the consenting process of four offshore wind farms off the east coast of Scotland in the Outer Forth (Inch Cape, Neart Na Gaoithe and Seagreen Alpha and Bravo). The RSPB objected to Marine Scotland's decision to grant consent to the projects, and sought a judicial review of the consent decision based upon the uncertainty of cumulative effects upon seabird populations [45, 46]. The original judgment in July 2016 upheld the RSPB's objections to the consent decision [45], although this judgment was overturned subsequently on appeal in May 2017 [46].

Earlier it was noted how keen the participants in this study were to discuss the interpretation of the Docking Shoal PVA and its implications for the Docking Shoal project (Section 4.2.4). Cook and Robinson [47] have attempted to address some of the main difficulties in determining population-level impacts and in interpretation of PVA. They proposed a novel framework to derive metrics of population size, population growth rate and the probability of the outcome; these metrics are then compared with decision criteria (Acceptable Biological Change, Decline Probability Difference, and Counterfactual of I mpacted to Unimpacted Populations), over the lifetime of a project. Such a framework is intended to enable regulators to make evidence-based decisions informed by more sophisticated estimates of risk in different scenarios. Nevertheless, it is clear from the judicial review of the Outer Forth projects that differences still persist between regulators and other stakeholders in preferred metrics and their subsequent interpretation for populationlevel impacts.

However, evidence-based decision-making requires evidence, and the lack of data on the marine environment - the "data void" referred to by a participant in Section 4.1.2 - continues to be an issue [17, $18,44,47,48]$. This is despite the increased use and acceptance of technology such as aerial video surveys, and research projects such as the Offshore Renewables J oint Industry Programme (ORJIP) Bird Collision Avoidance Study [49]. 
Six years on from the Docking Shoal consent refusal, it would appear that there is still much work to be done in filling the evidence gap and addressing methodological concerns.

\subsection{I ssues with Strategic Environmental Assessment (SEA)}

As mentioned in section 4.2.1, some of the interviewees alluded to deficiencies in terms of the initial offshore wind SEA (R2 Wind) such as it not being sufficiently robust when identifying environmental impacts. One participant went as far as saying the Round 2 SEA was "fundamentally flawed", specifically with regard to cabling issues.

Woolley (2015) [48] also discusses issues with offshore wind SEA processes in the context of the UK, and highlights that SEA has often been carried out "at such a high level...that they provide no more than a broad overview of the potential effects of offshore wind farm construction". Woolley goes on to contend that such initial broad SEAs would be more effective in limiting environmental impacts of offshore wind developments if followed up by a further more detailed assessment of specific proposed project sites, at the point where developers are choosing locations within a zone (such as the Greater Wash). However, it is still the subject of much debate in the industry as to how much datagathering and methodological development should be the responsibility of regulators during the SEA process, and which aspects should be the responsibility of project developers.

The RiCORE project reviewed marine renewable energy licensing and regulatory systems in a number of different European member states [25], and found considerable differences in practice in the way that offshore renewable SEA processes are conducted. Industry participants in the RiCORE project workshops [50] also generally felt that the SEA process "should be going further than it currently does in order to give developers more confidence in the areas that are more suitable for development".

The EU is currently carrying out a regulatory fitness and performance (REFIT) [51] evaluation of the SEA Directive to assess its performance and consider whether or not it is "fit for purpose". This evaluation will seek to find out how successful has the Directive been in progressing towards its objectives, ideally taking into account deficiencies such as those identified by interviewees.

\section{Conclusions}

The Docking Shoal project was cancelled after a process that incurred approximately $f 10 \mathrm{~m}$ of development costs over 8 years, which included a period of over three and half years between submission of the application and the Secretary of State's decision. 
This study concludes that the major risks and issues that impacted the Docking Shoal project were:

- lack of data on collision mortality,

- uncertainty and disagreement around PVA and mortality thresholds, and

- difficulties in assessing the cumulative impacts of neighbouring offshore wind projects.

These risks all contributed to the overall assessment made by the Secretary of State of how best to meet the UK's renewable energy policy targets out of a range of possible project deployment scenarios.

Lack of meaningful data on the marine environment in general continues to impact upon all parties involved in consenting decisions. Six years on from the Docking Shoal decision, there have been subsequent examples of offshore wind projects that have encountered serious issues due to impacts on seabirds (e.g. London Array II). Docking Shoal was one of the last projects to be considered under the Electricity Act 1989, so the consequences of its refusal were limited in terms of this soon-to-be-replaced process. It is also of course possible that the Docking Shoal project may have been refused consent if it had been considered under the new Planning Act 2008 process, although this is now a moot point. It is possible that the subsequent changes to planning legislation, via the introduction of the Planning Act 2008, have led to improved stakeholder engagement processes at an earlier stage, so that any issues with stakeholder engagement are addressed before a determination from the regulator is sought. This impact of the Planning Act 2008 on offshore wind projects is worthy of further study, as all participants were generally positive towards the stakeholder engagement provisions of the Planning Act 2008, and indeed only one subsequent offshore wind project (Navitus Bay) has been refused consent under it.

The present study also concludes that the Docking Shoal decision revealed a shift in approach from the regulator, from a "building block" approach to a more strategic assessment of cumulative impacts based on the totality of foreseeable projects in the pipeline, in the context of an increasing number of competing projects. This was broadly viewed to have been a positive development for consenting of future projects, lessening the pressure on developers to get applications in first (the "race for the line"), as the first project(s) in the pipeline may not necessarily be the best in terms of minimal environmental impact, or overall generating capacity delivered.

Since the Docking Shoal decision, the deployment of offshore wind in the Greater Wash area has continued. Of the projects that were considered in 2012 alongside Docking Shoal, the Dudgeon and Race Bank wind farms were finally completed and commissioned in 2017 
and 2018 respectively. The final installed capacity of the Dudgeon wind farm has a capacity of $402 \mathrm{MW}$, and Race Bank has a capacity of 573.3 MW [6], giving a combined capacity of 975.3 MW. The Triton Knoll project was granted consent in 2013, and is currently under construction, whilst the Lincs project was commissioned in 2013 [6]. Together with the Sheringham Shoal, Humber Gateway, Lynn and Inner Dowsing projects, there are currently 448 offshore wind turbines in the Greater Wash area, with a combined generating capacity of almost $2 \mathrm{GW}$ [6]. Further offshore, the giant Hornsea 1 and 2 projects have received planning consent to deliver 1.2 and 1.8 GW each; Project 1 is currently under construction [6].

In a wider UK and European context, The Crown Estate have recently begun stakeholder engagement for a potential fourth round of offshore wind project licences [52], and in European waters there is now $15.7 \mathrm{GW}$ of deployed capacity from over 4,100 installed turbines [53]. Perhaps one of the lasting impacts of the Docking Shoal decision has been a greater subsequent focus on cumulative impact assessments of developments in combination, as the number and scale of offshore wind developments has increased in the last decade.

However, even after consent has been granted, consent decisions have been subject to legal challenges precipitated by uncertainties in environmental impact assessment methodology, data collection and interpretation. A recent review of the Environmental Statements of nine UK offshore wind projects found considerable and "problematic" variability amongst the cumulative impact assessments of these projects [18]. As additional offshore wind projects continue to be deployed and proposed, the issues and uncertainties highlighted in the case of the Docking Shoal decision will continue to challenge project developers, stakeholders and regulators alike.

\section{Acknowledgements}

[to be provided later as these reveal affiliations] 


\section{References}

[1] RenewableUK, 2018a. Wind Energy Statistics. Available from: http://www. renewableuk.com/page/UKWEDhome (Accessed 28 February 2019)

[2] Crown Estate Act, 1961. Available from:

http://www. legislation.gov.uk/ukpga/Eliz2/9-10/55/contents

[3] Energy Act, 2004. Available from:

https://www. legislation.gov.uk/ukpga/2004/20/contents (Accessed 4 March 2019)

[4] RenewableUK, 2018b. Offshore Wind Project intelligence Global Offshore Wind 2018 Special Edition J une 2018. Available from: https://cdn.ymaws.com/www.renewableuk.com/resource/resmgr/p ublications/renewableuk_project_intellig.pdf (Accessed 28 February 2019)

[5] RenewableUK, 2016. Offshore Wind Energy - Owners Workshop Manual. Available from:

https://www. renewableuk.com/news/297780/Offshore-WindEnergy---Owners-Workshop-Manual.htm (Accessed 28 February 2019)

[6] 4C Offshore, 2018. Offshore wind farms - United Kingdom. Available from: https://www.4coffshore.com/windfarms/ (Accessed 28 February 2019)

[7] Centrica Energy, 2012. Docking Shoal Project history. Available from:

https: //web. archive. org/ web/20120309105040/ http: // www.centric a.com/files/pdf/centrica_energy/docking_shoal_project_history.pdf (Accessed 28 February 2019)

[8] Scottish Government, 2011. Blue Seas - Green Energy. A Sectoral marine plan for offshore wind energy in Scottish Territorial Waters. Available from:

https://www.gov.scot/Publications/2011/03/18141232/0 (Accessed 28 February 2019)

[9] G. Scott of Department of Energy \& Climate Change, 2012.

Decision Letter on Amended Application for consent to construct and operate an offshore wind farm known as Docking Shoal off the Coast of North Norfolk, 6 J uly 2012. Available from:

https: //itportal. beis.gov.uk/EI P/pages/projects/DockingDecision.pdf (Accessed 28 February 2019)

[10] G. Scott of Department of Energy \& Climate Change, 2015. Decision Letter on Planning Consent Application - Proposed Navitus Bay Wind Park, 11 September 2015. Available from: 
https: //infrastructure. planninginspectorate.gov.uk/wpcontent/ipc/uploads/projects/EN010024/EN010024-000055Secretary\% 20of\% 20State\% 20Decision\% 20Letter\% 20and\% 20State ment\% 20of\% 20Reasons.pdf

(Accessed 28 February 2019)

[11] Council of the European Communities Directive 92/43/EEC of 21 May 1992 on the conservation of natural habitats and of wild fauna and flora. Available from: https://eur-lex.europa.eu/legalcontent/EN/TXT/?uri=CELEX: 31992 L0043 (Accessed 28 February 2019)

[12] Council of the European Communities Directive 2009/147/EC of 30 November 2009 on the conservation of wild birds. Available from: https://eur-lex.europa.eu/legal-

content/EN/TXT/?uri=CELEX: 32009L0147 (Accessed 28 February 2019)

[13] Green, R.E., Langston, R.H.W., McCluskie, A., Sutherland, R., Wilson, J.D., 2016. Lack of sound science in assessing wind farm impacts on seabirds. Journal of Applied Ecology, 53, 1635-1641. https://doi.org/10.1111/1365-2664.12731

[14] Simas, T., O'Hagan, A. M., Callaghan, J.O., Hamawi, S., Magagna, D. et al., 2015. Review of consenting processes for ocean energy in selected European Member States. International Journal of Marine Energy 9, 41-59.

https://doi.org/10.1016/j.ijome.2014.12.001

[15] Wright, G., 2016. Regulating wave and tidal energy: An industry perspective on the Scottish marine governance framework. Marine Policy 65, 115-126.

https: // doi.org/10.1016/j.marpol.2015.12.014

[16] RenewableUK, 2013. Cumulative impact assessment guidelines: Guiding principles for cumulative impacts assessment in offshore wind farms. Available from:

https://nerc.ukri.org/innovation/activities/energy/offshore/cumulati ve-impact-assessment-guidelines/ (Accessed 28 February 2019)

[17] Masden, E.A., McCluskie, A., Owen, E., Langston, R.H.W., 2015. Renewable energy developments in an uncertain world: the case of offshore wind and birds in the UK. Marine Policy 51, 169-72 https://doi.org/10.1016/j. marpol.2014.08.006

[18] Willsteed, E.A., Jude, S., Gill, A.B., Birchenough, S.N.R., 2018. Obligations and aspirations: A critical review of offshore wind farm cumulative impact assessments. Renewable and Sustainable Energy Reviews 82, 2332-2345.

https://doi.org/10.1016/j.rser.2017.08.079 
[19] Gibson, E., Howsam, P., 2010. The legal framework for offshore wind farms: a critical analysis of the consents process. Energy Policy 38, 4629 - 4702

https://doi.org/10.1016/j.enpol.2010.04.029

[20] Accenture, 2012. Changing the scale of offshore wind. Available from:

https://www.accenture.com/t20150624T211115_w__/us-

en/_acnmedia/Accenture/Conversion-

Assets/DotCom/Documents/Global/PDF/Industries_10/Accenture-

Changing-Scale-Offshore-Wind.pdf (Accessed 28 February 2019)

[21] Leete, S., Xu, J., Wheeler, D., 2013. Investment Barriers and incentives for marine renewable energy in the UK: An analysis of investor preferences. Energy Policy 60, 866 - 875

https://doi.org/10.1016/j.enpol.2013.05.011

[22] MacAskill, A., and Mitchell, P., 2013. Offshore wind - an overview. WIREs Energy and Environment Volume 2 Issue 4 (J uly/August 2013) 374-383 https://doi.org/10.1002/wene. 30

[23] RenewableUK, 2011. Consenting Lessons Learned: An offshore wind industry review of past concerns, lessons learned and future challenges. London: RenewableUK

[24] RenewableUK, 2014. Managing Regulatory and Consenting Costs for Offshore Wind. Report for RenewableUK by PMSS Consultants. London: RenewableUK

[25] Le Lievre, C., O’Hagan, A.M., 2015. Legal and Institutional Review of National Consenting Processes. RiCORE Project, Work Package 2, Deliverable 2.2. Available from http://ricoreproject.eu/wp-content/uploads/2016/02/RiCORE-D2.2-LegalInstitutional-Review-Final-1.pdf (Accessed 28 February 2019)

[26] Council of the European Communities Directive 2001/42/EC of 27 J une 2001 on the assessment of the effects of certain plans and programmes on the environment. Available from: https://eurlex. europa.eu/legal-content/EN/TXT/ ?uri=CELEX: 32001 L0042 (Accessed 28 February 2019)

[27] Ministry of Housing, Communities and Local Government, 2005. Strategic Environmental Assessment Directive: guidance. Available from:

https://www.gov.uk/government/publications/strategicenvironmental-assessment-directive-guidance (Accessed 28 February 2019)

[28] Department of Trade and Industry (DTI), 2002. Future Offshore: A Strategic Framework for the Offshore Wind Industry. DTI, London. Available from https://tethys.pnnl.gov/sites/default/files/publications/A_Strategic_ Framework_for_the_Offshore_Wind_Industry.pdf (Accessed 28 February 2019) 
[29] Department of Trade and Industry, 2003. Offshore Wind Farm Development: Strategic Environmental Assessment (Wind R2). Available from:

https://www.gov.uk/government/consultations/offshore-wind-farmdevelopment-strategic-environmental-assessment-wind- $r 2$ (Accessed 08 November 2018)

[30] Department of Energy and Climate Change (DECC), 2009. Consultation outcome UK Offshore Energy Strategic Environmental Assessment (OESEA). Available from:

https://www.gov.uk/government/ consultations/uk-offshore-energystrategic-environmental-assessment-oesea (Accessed 28 February 2019)

[31] Global Wind Energy Council, 2017. Global statistics. Available from:

http://gwec.net/wp-content/ uploads/2018/04/6_Global-cumulativeOffshore-Wind-capacity-in-2017-1.jpg (Accessed 28 February 2019)

[32] The Guardian, 2013. Basking Sharks cause huge Scottish offshore wind farm to be shelved. Available from:

https: // www. theguardian.com/environment/2013/ dec/13/ baskingsharks-scottish-offshore-windfarm (Accessed 4 March 2019)

[33] Ministry of Housing, Communities and Local Government, 2014. Guidance: Use of Planning Conditions. Available from: https:// www.gov.uk/guidance/use-of-planning-conditions (Accessed 28 February 2019)

[34] Department of Trade and Industry (DTI), 2006. Appropriate Assessment with regard to London Array Wind Farm. Available from:

https: // itportal. beis.gov.uk/EI P/pages/ projects/LondonAAssessment .pdf (Accessed 28 February 2019)

[35] London Array, 2014. London Array Phase 2. Available from: http://www. londonarray.com/the-project-3/phase-2/ (Accessed 28 February 2019)

[36] Electricity Act, 1989. Available online:

https: // www. legislation.gov.uk/ukpga/1989/29/contents (Accessed 28 February 2019)

[37] Planning Act, 2008. Available online:

https://www. legislation.gov.uk/ukpga/2008/29/contents (Accessed 28 February 2019)

[38] Glaser, B., Strauss, A., 1967. The Discovery of Grounded Theory: Strategies for Qualitative Research, p114. ISBN:

9780202302607. 
[39] Saunders, M., Lewis, P., Thornhill, A., 2016. Research Methods for Business Students $7^{\text {th }}$ ed, FT Prentice Hall, Harlow, UK, p52-53, 407. ISBN: 9781292016641

[40] QSR International, 2015. NVivo qualitative data analysis Software; QSR International Pty Ltd. Version 11, 2015

[41] Department of Energy and Climate Change (DECC), 2012. Record of the Appropriate Assessment undertaken for applications under Section 36 of the Electricity Act 1989. Projects: Docking Shoal offshore wind farm (as amended), Race Bank offshore wind farm (as amended), Dudgeon offshore wind farm, December 2011, updated J une 2012. Available at:

https: / /itportal. beis.gov.uk/EIP/pages/projects/AAGreaterWash. pdf (Accessed 28 February 2019)

[42] J NCC, SPA Description of the North Norfolk Coast, 2001. Available at: http: //jncc. defra.gov.uk/default. aspx?page $=2008$ (Accessed 28 February 2019)

[43] Natural England, 2015. Developers: get environmental advice on your planning proposals. Available at:

https://www.gov.uk/guidance/developers-get-environmentaladvice-on-your-planning-proposals (Accessed 28 February 2019).

[44] Cook, A.S.C.P., Humphreys, E.M., Bennet, F., Masden, E.A., Burton, N.H.K. (2018). Quantifying avian avoidance of offshore wind turbines: Current evidence and key knowledge gaps. Marine Environmental Research, 140, 278-288.

https://doi.org/10.1016/j.marenvres.2018.06.017

[45] Scottish Courts and Tribunals, 2016. Petition of the Royal Society for the Protection of Birds for Judicial Review: Opinion of Lord Stewart, [2016] CSOH 103. Available from:

https://www.scotcourts.gov.uk/searchjudgments/judgment?id=d69419a7-8980-69d2-b500-ff0000d74aa7 (Accessed 28 February 2019)

[46] Scottish Courts and Tribunals, 2017. Reclaiming motions in the petitions by the Royal Society for the Protection of Birds against the Scottish Ministers and (First) Inch Cape Offshore Ltd; (Second) Neart Na Gaoithe Offshore Wind Ltd; and (Third) Seagreen Wind Energy Ltd for Judicial Review. Opinion of the Court, [2017] CSIH 31. Available from: https://www.scotcourts.gov.uk/searchjudgments/judgment?id=116833a7-8980-69d2-b500-ff0000d74aa 7 (Accessed 28 February 2019)

[47] Cook, A.S.C.P., and Robinson, R.A. (2017). Towards a framework for quantifying the population-level consequences of anthropogenic pressures on the environment: The case of seabirds and windfarms. J ournal of Environmental Management, 190, 113121. http://dx.doi.org/10.1016/j.jenvman.2016.12.025 
[48] Woolley, O. (2015). Ecological Governance for Offshore Wind Energy in UK Waters: Has an Effective Legal Framework Been Established for Preventing Ecologically Harmful Development? International J ournal of Marine and Coastal Law,30, 765-793. https://doi.org/10.1163/15718085-12341379

[49] The Carbon Trust, 2018. ORJ IP Bird Collision Avoidance Study. Available from: AlQQ (Accessed 28 February 2019)

[50] O'Hagan, A.M., Nixon, C. and Mascarenhas, P. (2015) Report from the Workshop on Marine Renewable Energy Licensing and Regulatory Systems. Deliverable 2.1, RICORE Project. http://ricore-project. eu/wp-content/uploads/2015/10/RI COREWorkshop2ReportFinalencrypt.pdf (Accessed 28 February 2019)

[51] European Commission, 2018. REFIT Evaluation of the SEA Directive. Available from: http://ec.europa.eu/environment/eia/searefit.htm (Accessed 28 February 2019)

[52] The Crown Estate, 2018. The Crown Estate launches a second phase of engagement on new offshore wind leasing following positive market response. Available from: https://www.thecrownestate.co.uk/en-gb/media-andinsights/news/2018-the-crown-estate-launches-a-second-phase-ofengagement-on-new-offshore-wind-leasing-following-positivemarket-response/ (Accessed 28 February 2019)

[53] Wind Europe 2018. Offshore wind in Europe: Key trends and statistics 2017. Available from https://windeurope.org/wpcontent/ uploads/files/about-wind/statistics/WindEurope-AnnualOffshore-Statistics-2017.pdf (Accessed 28 February 2019) 